\title{
Evaluation of the Safety and Effectiveness of the Rapid Flow Expulsion Maneuver to Clear Subglottic Secretions in Vitro and in Vivo
}

\author{
Jie Li MSc RRT-NPS RRT-ACCS, Yajuan Zong, Quan Zhou, Huaping Dai MD PhD, and \\ Chen Wang MD PhD
}

\begin{abstract}
BACKGROUND: Clearing subglottic secretions has been proved to reduce ventilator-associated pneumonia. A manual method named the rapid flow expulsion maneuver was developed to clear subglottic secretions. This study evaluates its safety and effectiveness and analyzes the influential factors. METHODS: This study was composed of 2 parts. In an in vitro study, secretions were instilled directly to the area above the cuff in an intubated tracheal model. Secretions were expelled by the rapid flow expulsion maneuver with different volumes and peak flows in 3 tracheal positions $\left(0,15\right.$, and $\left.30^{\circ}\right)$. At each tracheal position, the maneuver was repeated twice, unless secretions above the cuff were $<0.5 \mathrm{~mL}$. In an in vivo study, subglottic secretions were suctioned via subglottic secretion drainage and then were cleared by the rapid flow expulsion maneuver. After the initial maneuver, methylene blue $(2 \mathrm{~mL})$ was instilled above the cuff, and the maneuver was performed again. The subject's sputum color was then recorded over $24 \mathrm{~h}$. RESULTS: In the in vitro study, no aspiration was observed in the 277 maneuvers completed. Subglottic secretions were visibly expelled in 167 of 277 maneuvers $(60.3 \%)$, and the median clearance efficiencies of the 3 consecutive maneuvers were 39.6, 6.3, and $0.4 \%$. In the 108 first maneuvers, $93(86.1 \%)$ produced visible secretions. Multiple linear regression models were used to identify predictors of clearance efficiency: tracheal position $(P<.001)$, flow $(P=.041)$, and secretion viscosity $(P=.017)$. In the in vivo study, 77 rapid flow expulsion maneuvers were completed after suctioning via subglottic secretion drainage in 16 subjects, and the maneuvers collected $221.5 \mathrm{~mL}$ of secretions. No aspiration was observed over $24 \mathrm{~h}$. CONCLUSIONS: The rapid flow expulsion maneuver was safe and effective to clear subglottic secretions. The first maneuver was the most effective to expel the majority of secretions. Supine position and high peak flow improved the clearance efficiency. Key words: subglottic secretion drainage; ventilator-associated pneumonia. [Respir Care 2017;62(8):1007-1013. () 2017 Daedalus Enterprises]
\end{abstract}

\section{Introduction}

Ventilator-associated pneumonia (VAP) is the most frequent infection occurring in patients who are admitted to

\footnotetext{
Ms Li is affiliated with the Department of Cardiopulmonary Sciences, Division of Respiratory Care, Rush University Medical Center, Chicago, Illinois. Ms Li and Dr Dai are affiliated with Pulmonary and Critical Care Medicine, Beijing Chao-Yang Hospital, Capital Medical University, Beijing Institute of Respiratory Medicine, Beijing, China. Ms Zong is affiliated with the ICU, 2nd Yixing Hospital, Wuxi, Jiangsu, China. Mr Zhou is affiliated with the ICU, Yijishan Medical University Hospital, Wuhu, Anhui, China. Drs Dai and Wang are affiliated with Pulmonary and Critical Care Medicine, China-Japan Friendship Hospital, Beijing, China.
}

The authors have disclosed no conflicts of interest. the ICU. ${ }^{1}$ VAP is also a substantial clinical and economic burden. ${ }^{2}$ A well-known cause of VAP is the secretions accumulated in the subglottic space; thus, preventing aspiration reduces the incidence of VAP. ${ }^{3}$ Holding secretions above the cuff of an artificial airway to avoid secretion leakage into the lower airway has been shown to prevent early VAP. However, evidence of prevention in late-onset VAP is less robust. ${ }^{4}$ This suggests that microaspiration of subglottic secretions may be postponed, but not

Correspondence: Chen Wang MD PhD, China-Japan Friendship Hospital, No. 2 Yinghuayuan Dong Street, Beijing 100029, China. E-mail: cyhrt@sina.cn.

DOI: $10.4187 /$ respcare. 05348 
eliminated, ${ }^{4}$ plus a high density of pathogens may develop in the subglottic secretions over time. Although secretions can be completely impeded above the cuff, once the cuff is deflated (eg, at extubation or repositioning of the artificial airway), the secretions still fall down to the lower airway, which may cause VAP. Therefore, subglottic secretion drainage becomes important.

\section{See the Related Editorial on Page 1111}

Over the years, clinicians have used special artificial airways with an independent dorsal lumen to evacuate subglottic secretions; this technique was referred to as subglottic secretion drainage. A systematic review of 17 eligible trials with 3,369 subjects showed that subglottic secretion drainage tubes helped to reduce VAP rates. ${ }^{5}$ However, the reported failure to aspirate subglottic secretions using subglottic secretion drainage had an incidence of $34 \%$ in the study by Rello et $\mathrm{al}^{6}$ and $48 \%$ in the study by Dragoumanis et al. ${ }^{7}$ This high incidence of failure raised safety concerns with subglottic secretion drainage, because the suction port was apparently occluded by suctioned tracheal mucosa, ${ }^{7}$ which was the dominant cause of suction lumen dysfunction and a cause of the tracheal mem-

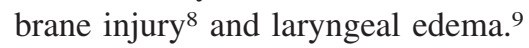

Other ways have been sought to clear subglottic secretions, such as utilization of high PEEP or plateau pressure generated by a ventilator. ${ }^{10,11}$ While the cuff is deflated, the large pressure gradient produces high flow to flush subglottic secretions to the oral cavity. This method was tested by Safdari et $\mathrm{al}^{11}$; the resultant VAP rate was significantly lower than for the group with routine oropharyngeal suctioning $(26.3 \%$ vs $47.4 \%, P=.04)$.

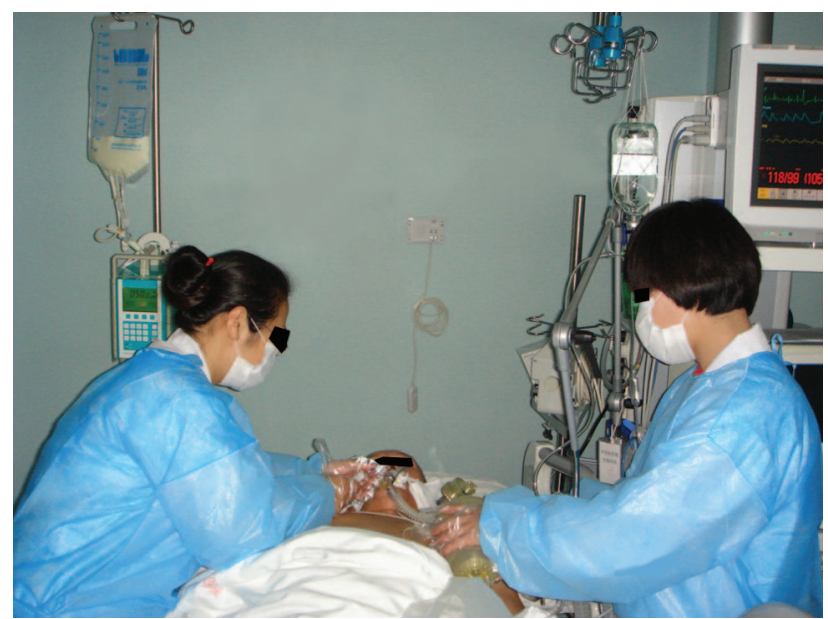

Fig. 1. Respiratory therapists implementing the rapid flow expulsion maneuver to clear subglottic secretions for an intubated subject.

\section{QUICK LOOK}

\section{Current knowledge}

Clearing subglottic secretions has been proved to reduce ventilator-associated pneumonia; the subglottic secretion drainage airways have been widely used over the years. However, the reported failure to aspirate secretions and the occlusion caused by suctioned tracheal mucosa raised safety concerns.

\section{What this paper contributes to our knowledge}

To clear subglottic secretions, we developed a manual method: the rapid flow expulsion maneuver. Our study showed that this maneuver, which requires no special artificial airway, clears secretions above the cuff more efficiently and cost-effectively than do subglottic secretion drainage tubes. Consequently, this maneuver might be applied to clear subglottic secretions in a wider range of patient populations.

A manual method using high-flow air produced by a manual resuscitator to expel secretions from the subglottic space to the oral cavity has been used since the 1990s in Beijing Chaoyang Hospital (Fig. 1).12 This method, named the rapid flow expulsion maneuver, has been utilized by $>50$ ICUs in mainland China. ${ }^{13}$ The rationale of this maneuver is to enhance the patient's coughing to expel the subglottic secretions during cuff deflation. When an intubated patient exhales or coughs, if the cuff is deflated at the same time, patient's rapid expiratory flow will pass the space around the deflated cuff to bring the subglottic secretions toward the oropharynx, and then these secretions can be easily removed by oral suction. However, the expiratory flow generated by the intubated patient may not be sufficient to expel the subglottic secretions. It is enhanced or amplified by the high flow produced via squeezing a resuscitation bag. The key to success of this maneuver is the cooperation between the 2 operators performing the maneuver and the timing of the rapid flow delivery; the resuscitation bag must be squeezed at the beginning of expiration, and the cuff must be deflated at exactly the same time (Fig. 2). The purpose of this study is to evaluate the safety and effectiveness of this maneuver and to analyze the factors that influence its efficiency.

\section{Methods}

\section{Study Design}

To assess the effects of rapid flow expulsion maneuver as well as to explore the possible influential factors, an 


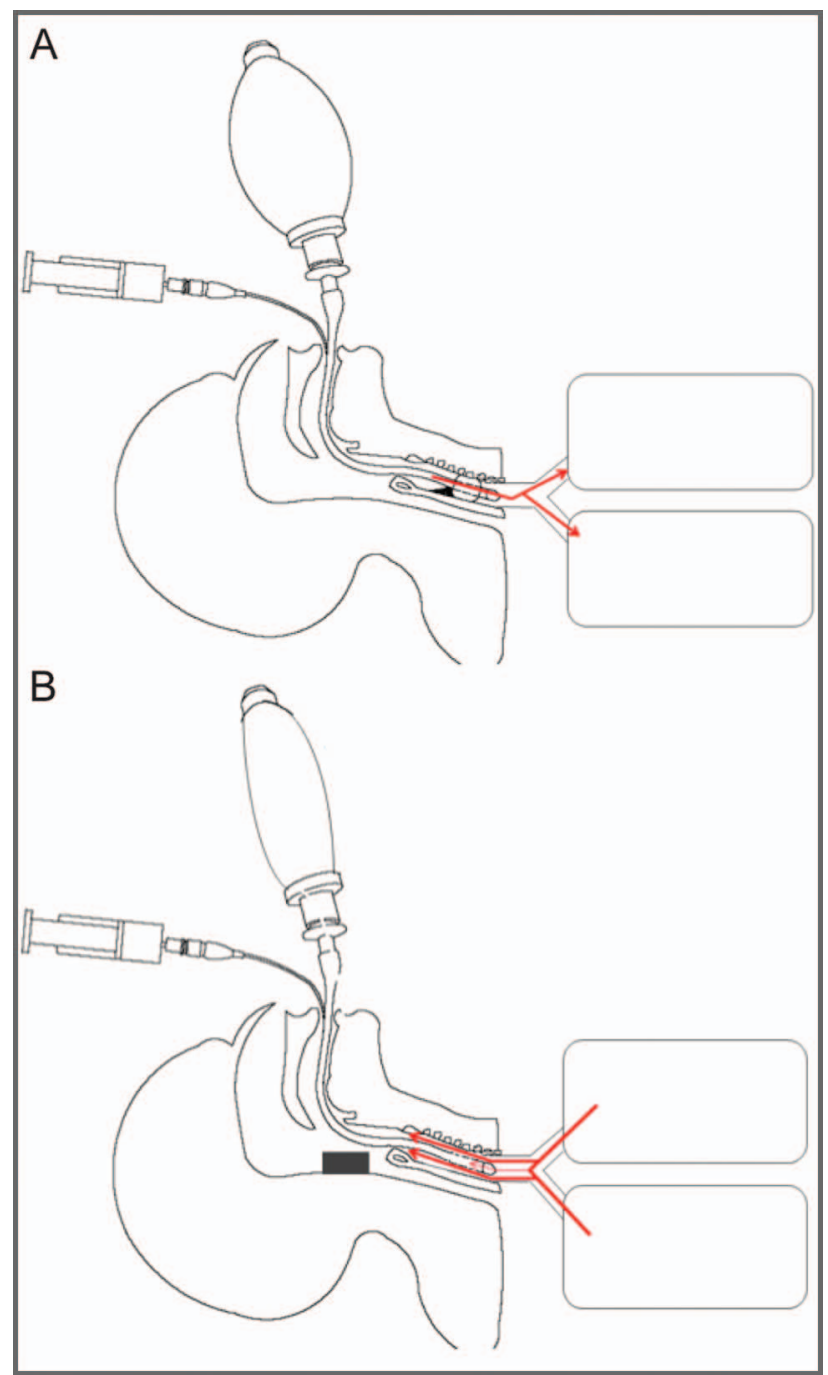

Fig. 2. The rapid flow expulsion maneuver to clear subglottic secretions. A: Step 1: Deliver one breath via resuscitation bag. B: Step 2: At the beginning of expiration, the operator squeezes the resuscitation bag to produce high flow against subject's exhalation flow. At the same time, the assistant deflates the cuff, so that the flows are forced to expel through the space around the deflated cuff and to bring the subglottic secretions to the mouth.

in vitro evaluation was conducted to identify key factors to optimize the maneuver, followed by an in vivo study to confirm the safety and effects of the maneuver in comparison with a subglottic secretion drainage tube. The in vivo study was approved by the institutional review board of Beijing Chaoyang hospital. This study was implemented in Beijing Chaoyang hospital. Inclusion criteria were subjects who were orally intubated with subglottic secretion drainage endotracheal tubes, and estimated duration of invasive mechanical ventilation was $>48 \mathrm{~h}$, whereas exclusion criteria were PEEP $\geq 10 \mathrm{~cm} \mathrm{H}_{2} \mathrm{O}$ and $\mathrm{F}_{\mathrm{IO}_{2}} \geq 0.8$, severe pulmonary bullae and history of

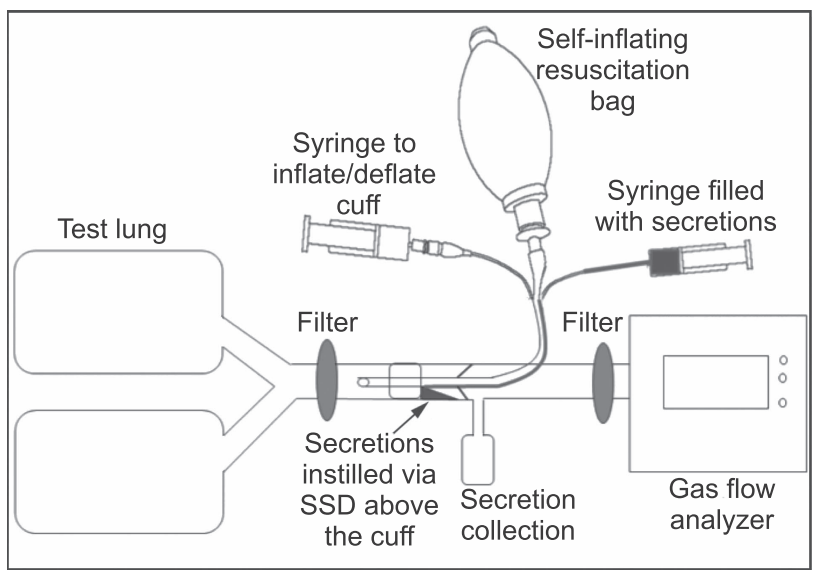

Fig. 3. Diagram of the in vitro model. SSD = subglottic secretion drainage.

pneumothorax, contraindications of supine position (eg, head and/or neck injury, intracranial pressure $>20 \mathrm{~mm}$ $\mathrm{Hg}$, recent epidural spinal infusion or spinal anesthesia), unstable hemodynamics, and tracheotomy. Eligible subjects were enrolled and given informed consent.

\section{In Vitro Study}

An artificial trachea (2.2-cm diameter, clear polyvinyl chloride cylinder) with representative human vocal cords was connected with a test lung (B\&B Medical, North Highlands, California) (see Fig. 3). The trachea was intubated with an 8.0-mm inner diameter subglottic secretion drainage endotracheal tube (Mallinckrodt-Medtronic, Minneapolis, Minnesota), and the cuff was inflated to $25-30 \mathrm{~cm} \mathrm{H}_{2} \mathrm{O}$. The endotracheal tube was connected to a self-inflating resuscitation bag (Galemed Corporation, Taipei, Taiwan). Right above the vocal cords, a collection bottle was connected with the trachea via a flexible soft tube. At the other end of the trachea, investigators connected a gas flow analyzer (Fluke Biomedical VT PLUS HF, Cleveland, Ohio). Two filters were utilized: one was placed between the test lung and the tip of endotracheal tube, to capture any subglottic secretions that might have leaked to the lower airway during the operation; the other one was placed between the collection bottle and the gas flow analyzer to prevent the secretions being expelled to the analyzer. Four $\mathrm{mL}$ of secretions with different viscosities were collected from clinical patients and instilled via subglottic secretion drainage directly into the area above the cuff of the endotracheal tube. The breath was delivered via a resuscitation bag by the investigators, and expulsion volume and peak flow for expelling secretions were measured by a gas flow analyzer. The trachea model was placed at 0,15 , and $30^{\circ}$ from horizontal. In each tracheal position, up to 3 maneuvers were utilized to flush the subglottic secretions out of 
the vocal cords. The quantity of the maneuvers depended on the clearance of the secretions. No additional maneuvers were indicated if $0.5 \mathrm{~mL}$ of secretions were left above the cuff. After each maneuver, secretions expelled to above the vocal cords were collected in the collection bottle and weighed. The clearance efficiency was calculated by the formula: percentage of clearance efficiency $=$ amount of secretions expelled to above the vocal cords by the maneuver/the amount of secretions above the cuff before the maneuver).

\section{In Vivo Study}

Subglottic secretions were suctioned via subglottic secretion drainage in semi-Fowler's position. Immediately after this procedure, subjects were placed in the supine position, and the rapid flow expulsion maneuver was utilized to clear subglottic secretions, which were collected and weighed. Then $2 \mathrm{~mL}$ of methylene blue was instilled above the cuff via subglottic secretion drainage, and the maneuver was performed again. The color of tracheal secretion was observed and recorded over $24 \mathrm{~h}$ to track aspiration. This entire procedure was implemented every other day in the enrolled subjects until extubation. Complications (eg, air leak, hemodynamic instability, etc) were monitored.

All of the subjects were placed in supine position during the rapid flow expulsion maneuver. Enteral feeding was suspended $30 \mathrm{~min}$ before the maneuver, and a 2-min preoxygenation period was offered. Cuff pressure was maintained at $25-30 \mathrm{~cm} \mathrm{H}_{2} \mathrm{O}$. Two operators performed the maneuver, and one stood at each side of the subject's bed. Oral secretions were suctioned, and then the subject was disconnected from the ventilator and connected to the selfinflating resuscitation bag (Fig. 1). One breath with tidal volume was delivered to the subject, and then at the beginning of expiration, the operator squeezed the resuscitation bag to produce high flow; at the same time, the other operator deflated the cuff (Fig. 2). At the end of the maneuver, the cuff was re-inflated, and secretions that were flushed to the oral cavity were suctioned and collected. During the maneuver, the clinicians monitored subjects' vital signs, $\mathrm{S}_{\mathrm{pO}_{2}}$, heart rhythm, and subjective complaints. The maneuver would be terminated if any of the following criteria were met: (1) $\mathrm{S}_{\mathrm{pO}_{2}} \leq 90 \%$; (2) heart rate increased by $20 \%$; (3) subject's discomfort; or (4) new-onset irregular heart rhythm.

Subglottic secretion drainage was performed at a pressure of $-100 \mathrm{~mm} \mathrm{Hg}$ with a 20 -s interval and duration of $8 \mathrm{~s} 3$ times/d while subjects were intubated. Five $\mathrm{mL}$ of air was injected via the drainage lumen to maintain patency before suctioning.

\section{Statistics}

The continuous and categorical variables of volume, flow, amount of secretions above the cuff, viscosity of secretions, and clearance efficiency were analyzed using descriptive statistics. The Kolmogorov-Smirnov statistical tests and histogram were used to test the normality of distribution for these variables. Data were stratified by groups (with visible secretions vs without visible secretions), and differences in the above-stated variables were compared between groups using the Student $t$ test for variables of flow and tidal volume and the Mann-Whitney $\mathrm{U}$ test for variables of secretion viscosities and amount of secretion above the cuff. A chi-square test was used to determine the association between different tracheal positions and visible secretions. Dummy variables were created for the different tracheal positions. Binary stepwise logistic regression analysis was performed to assess the impact of a number of factors (amount of the secretions above the cuff, secretion viscosities, flow, tracheal positions at 15 and $30^{\circ}$ ) on the likelihood that secretions above the cuff could be cleared out (yes/no) in all of the maneuvers $(n=277)$.

To further explore how these factors predict clearance efficiency of secretions above the cuff, we used a multiple linear regression to assess only the 108 first maneuvers, since the first maneuver was the most effective to clear the majority of secretions. The bivariate relationship between the efficiency of secretion clearance and the influential factors was investigated using Pearson's correlation analysis. Analysis of variance was used to assess the difference in the clearance efficiency and tracheal positions $(0,15$, and $30^{\circ}$ ). The following variables were entered into a stepwise regression model: secretion viscosity, flow, tracheal position at $15^{\circ}$, and tracheal position at $30^{\circ}$. A $P$ value of $<.05$ was considered to be statistically significant for all predictor variables. Data analysis was conducted with SPSS 23.0 for Windows (SPSS, Chicago, Illinois).

\section{Results}

\section{In Vitro Study}

No aspiration was observed in the 277 rapid flow expulsion maneuvers completed. The median (interquartile range) clearance efficiencies of the 3 consecutive maneuvers were $39.6 \%$ (18.1-65.4\%), 6.3\% (0-18\%), and $0.4 \%$ $(0-9.1 \%)$. Subglottic secretions were visibly expelled in 167 of 277 maneuvers (60.3\%), whereas they were visibly expelled in the first maneuver in $86.1 \%$ of cases $(93$ of 108) $(P<.001)$. Volume, flow, tracheal position, and viscosity of the secretions are compared in Table 1 between the groups that cleared the secretions visibly and those that did not. In the logistic regression analysis, the 
Table 1. In Vitro Comparison Between the Groups With Visible Secretions and Without Visible Secretions

\begin{tabular}{|c|c|c|c|}
\hline Parameters & Visible Secretions & No Visible Secretion & $P$ \\
\hline$n$ & 167 & 110 & \\
\hline Tidal volume, mean $\pm \mathrm{SD} \mathrm{mL}$ & $780.2 \pm 182.8$ & $771.7 \pm 153.5$ & .68 \\
\hline Flow, mean $\pm \mathrm{SD} \mathrm{L} / \mathrm{min}$ & $92.3 \pm 22.1$ & $90.4 \pm 17.5$ & .43 \\
\hline Viscosity of secretions, median (IQR) $\mathrm{mm} / \mathrm{min}$ & $6.4(1.0-37.9)$ & $6.4(1.0-22.8)$ & .65 \\
\hline Amount of secretions above the cuff, median (IQR) $g$ & $3.9(2.7-4.0)$ & $2.8(1.6-3.7)$ & $<.001$ \\
\hline Tracheal position, $n(\%)$ & & & .039 \\
\hline $0^{\circ}$ & $103(61.7)$ & $52(47.3)$ & \\
\hline $15^{\circ}$ & $33(19.8)$ & $25(22.7)$ & \\
\hline $30^{\circ}$ & $31(18.6)$ & $33(30.0)$ & \\
\hline
\end{tabular}

Table 2. Clearance Efficiency and Flow at Different Tracheal Positions in the First Maneuver In Vitro

\begin{tabular}{lcccc}
\hline \hline \multicolumn{1}{c}{ Parameters } & $0^{\circ}$ & $15^{\circ}$ & $30^{\circ}$ & $P$ \\
\hline$n$ & 61 & 22 & 25 & \\
$\begin{array}{l}\text { Clearance efficiency in } \\
\text { the first maneuver, } \\
\text { mean } \pm \text { SD \% }\end{array}$ & $55 \pm 26$ & $29 \pm 27$ & $23 \pm 19$ & $<.001$ \\
$\begin{array}{l}\text { Flow, mean } \pm \text { SD } \\
\text { L/min }\end{array}$ & $92.9 \pm 2.2$ & $87.2 \pm 2.0$ & $92.3 \pm 2.3$ & .58 \\
\hline
\end{tabular}

amount of secretions above the cuff was associated with visible secretions (odds ratio $=3.28,95 \%$ CI 2.37-4.55, $P<.001$ ), whereas an elevated tracheal position and secretion viscosity were associated with the failure to clear secretions above the cuff.

In the 108 first maneuvers, multiple linear regression models were used to identify predictors of clearance efficiency. The comparisons of clearance efficiency and flow among different tracheal positions are listed in Table 2. The variables (secretion viscosity, flow, tracheal position at $15^{\circ}$, and tracheal position at $30^{\circ}$ ) were marginally associated with the outcome variable. All of the 4 variables that were entered into the stepwise regression model were significant predictors of clearance efficiency: Tracheas placed at $15^{\circ}(P<.001)$ and $30^{\circ}(P<.001)$ were independent predictors of clearance efficiency, whereas the flow $(P=.041)$ and secretion viscosity $(P=.02)$ also predicted the clearance efficiency. The regression model explained $32.1 \%$ of total variance in clearance efficiency of secretions above the cuff. The regression model for secretion clearance is $\mathrm{Y}=0.387+0.002 \times$ (flow) $0.002 \times($ secretion viscosity $)-0.247 \times($ tracheal position at $\left.15^{\circ}\right)-0.312 \times\left(\right.$ tracheal position at $\left.30^{\circ}\right)$, where $1=$ yes and $0=$ no for tracheal positions at 15 and $30^{\circ}$. There was no significant collinearity observed (tolerance $>0.20$, variance inflation factor $<0.50$ ).

\section{In Vivo Study}

Ten female and 6 male subjects were enrolled, with median (interquartile range) age 65 y (35-75 y). They were intubated with $7.0-8.0-\mathrm{mm}$ subglottic secretion drainage endotracheal tubes. Seventy-seven maneuvers were completed, which yielded $2 \mathrm{~mL}$ (interquartile range $1-3 \mathrm{~mL}$ ) of secretions/maneuver for a total of $221.5 \mathrm{~mL}$ of secretions. Each maneuver was completed immediately after suctioning via subglottic secretion drainage. None of the maneuvers were terminated. No aspiration of methylene blue was observed, and no complications were observed for $24 \mathrm{~h}$ after the maneuvers.

\section{Discussion}

Our study demonstrates that the rapid flow expulsion maneuver results in efficient removal of subglottic secretions. The influential factors related to its efficiency are explored and discussed below.

\section{Frequency of the Maneuver}

The leakage of subglottic secretions depends on the pressure above and below the cuff, which refers to the amount of the secretions above the cuff and PEEP. When the amount of secretions above the cuff was $<4 \mathrm{~mL}$ in Young's bench model with a PEEP setting at $5 \mathrm{~cm} \mathrm{H}_{2} \mathrm{O}$, leakage of subglottic secretions was significantly reduced. ${ }^{14}$ Moreover, if there were only few secretions above the cuff, Suys et a ${ }^{15}$ found that the subject's tracheal mucosa might be prolapsed adjacent to the subglottic suction port while using subglottic secretion drainage to suction. This prolapse also contributed to one third of subglottic secretion drainage dysfunction in the study by Rello et al ${ }^{6}$ and $42.5 \%$ blockade of the subglottic suction port in the study by Dragoumanis et $\mathrm{al}^{7}$ Therefore, the current preferred procedure is not continuous but intermittent suctioning of the 
accumulated subglottic secretions. ${ }^{16,17}$ Similarly, our study found that it was less possible to clear secretions visibly if only a few secretions existed above the cuff. The subglottic secretions produced within $24 \mathrm{~h}$ were estimated to be $7.8 \pm 1.1 \mathrm{~mL}$, according to Greene et al ${ }^{18}$; thus, it is more reasonable to utilize the rapid flow expulsion maneuver intermittently (eg, every $6-8 \mathrm{~h}$ ). The actual frequency depends on the quantity of patients' oral secretions.

\section{Subject Position}

The patient's tracheal position is also critical for secretion drainage, because gravity plays an important role in draining subglottic secretions. Compared with semirecumbent plus prone position, Trendelenburg plus prone position accelerated the mucus clearance, improved expiratory-inspiratory flow, avoided aspiration, and finally prevented VAP in the study by Li Bassi et al ${ }^{19}$ Those authors offer a possible explanation: The oropharyngeal secretions are removed by gravity. Similar to their findings, our study also shows that the supine position at $0^{\circ}$ works more efficiently than the trachea positioned at 15 and $30^{\circ}$. We did not test the efficiency of our maneuver with Trendelenburg and/or prone position, but it can be expected that the clearance efficiency would be higher than in the supine position. However, Trendelenburg and/or prone position may not be feasible in clinical practice, because critically ill patients may not easily tolerate those positions.

\section{Flow Used in the Maneuver}

Among 10 maneuvers to clear subglottic secretions in the study by Hodd et al, ${ }^{10}$ PEEP at $35 \mathrm{~cm} \mathrm{H}_{2} \mathrm{O}$ was shown to be the most efficient. However, the clinical feasibility is doubtful, because of its high potential to cause barotrauma, ${ }^{20}$ as well as tolerance, particularly in awake patients who may not tolerate such high pressures. It is assumed that once the endotracheal tube cuff is deflated, the large positive pressure gradient will generate high constant flow around the cuff. The same mechanism was utilized with plateau pressure generated by a 2-s inspiratory hold in the study by Safdari et al ${ }^{11}$ With that being said, the key step to clear subglottic secretions is the rapid flow flushed into the space between the deflated cuff and the trachea membrane. This mechanism explains our findings that flow is associated with clearance efficiency. However, in our study, the rapid flow is produced by investigators via the resuscitation bag and not by the ventilator. The potential advantage of our maneuver is that it avoids high constant airway pressure for the patients because the cuff is deflated when the rapid flow is delivered to the patient. We did not measure the exact pressure, but we speculate that the pressure in the airway and alveoli would decrease when the cuff is deflated; thus, our maneuver might be safer than simply using PEEP or plateau pressure at or above $35 \mathrm{~cm}$ $\mathrm{H}_{2} \mathrm{O}$. Furthermore, in our 20 years' clinical experience using this maneuver among thousands of adult patients, no complications have been observed.

\section{Collaboration in Deflating Cuff and Compressing Resuscitation Bag}

Besides using high PEEP to clear subglottic secretions, another common way to clear subglottic secretions is by compressing a self-inflating bag during cuff deflation. According to the 2 large-scale surveys of anesthesiologists ${ }^{21}$ and senior ICU nurses ${ }^{22}$ in the United Kingdom, the resuscitation bag was utilized before extubation. However, those studies did not report the details of how to use the resuscitation bag, especially the cooperation involved in deflating the cuff and compressing the resuscitation bag simultaneously. Our study, as well as our clinical experience, strongly suggests that the collaboration of the 2 operators plays the key role in the success of the rapid flow expulsion maneuver, and this collaboration differentiates our maneuver from others that use a resuscitation bag. We observed that aspiration occurred if deflating the endotracheal tube cuff was not perfectly synchronized with squeezing the resuscitation bag. That observation might explain the high percentage of aspiration in the study by Hodd. ${ }^{10}$ It is also why we always check staff's competency before their clinical practice.

One limitation in our study is that we did not compare the clinical outcome of subjects using the maneuver with using a subglottic secretion drainage tube. Our randomized controlled trial (ClinicalTrials.gov registration NCT02032849) is currently enrolling subjects to investigate the effect of the rapid flow expulsion maneuver versus subglottic secretion drainage on VAP and its efficiency of clearing subglottic secretions. The other limitation in the use of the maneuver is among patients with high ventilator settings (eg, PEEP $>10 \mathrm{~cm} \mathrm{H}_{2} \mathrm{O}$ ), because the maneuver might cause a risk of losing PEEP when disconnecting patients from the ventilator. Although the interval between disconnection from the ventilator and connection to the resuscitation bag with a PEEP valve is short, there is still a risk of losing PEEP, which may cause alveoli decruitment. Thus, this maneuver may be contraindicated in patients who require high ventilator support. For these patients, it is worth attempting to use the ventilator instead of manual operation to mimic the rapid flow maneuver to clear subglottic secretions. Future studies may compare these 2 procedures. No matter which procedure is used, we emphasize that clinicians require training and practice, especially in synchronizing the necessary collaboration between 2 operators. 


\section{Rapid Flow Expulsion Maneuver}

\section{Conclusions}

The rapid flow expulsion maneuver that we developed to clear subglottic secretions has been safe and effective in both in vitro and in vivo studies and was well tolerated by subjects. The first maneuver is the most effective; it cleared $\sim 40 \%$ of the subglottic secretions. The amount of secretions above the cuff and the tracheal position decide whether secretions can be visibly expelled or not, whereas the tracheal position and flushing flow generated via resuscitation bag appear to predict the efficiency of secretion clearance. These results suggest that the rapid flow expulsion maneuver needs to be utilized intermittently with high peak flow in supine position. The in vivo study shows that the rapid flow expulsion maneuver expelled more secretions even after suctioning via subglottic secretion drainage. No aspiration of the subglottic secretions was observed during and after maneuvers in either the in vitro or the in vivo study.

\section{ACKNOWLEDGMENTS}

We thank J. Brady Scott MSc RRT-ACCS FAARC, Tyler Weiss MSc RRT-ACCS AE-C and James B Fink PhD RRT FAARC for reviewing the manuscript and Sharon Foley PhD RDN LDN for reviewing statistics.

\section{REFERENCES}

1. Guillamet CV, Kollef MH. Ventilator associated pneumonia in the ICU: where has it gone? Curr Opin Pulm Med 2015;21(3):226-231.

2. Kallet RH. The vexing problem of ventilator-associated pneumonia: observations on pathophysiology, public policy, and clinical science. Respir Care 2015;60(10):1495-1508.

3. Haas CF, Eakin RM, Konkle MA, Blank R. Endotracheal tubes: old and new. Respir Care 2014;59(6):933-952; discussion 952-955.

4. Blot SI, Rello J, Koulenti D. The value of polyurethane-cuffed endotracheal tubes to reduce microaspiration and intubation-related pneumonia: a systematic review of laboratory and clinical studies. Crit Care 2016;20(1):203.

5. Caroff DA, Li L, Muscedere J, Klompas M. Subglottic secretion drainage and objective outcomes: a systematic review and metaanalysis. Crit Care Med 2016;44(4):830-840.

6. Rello J, Soñora R, Jubert P, Artigas A, Rué M, Vallés J. Pneumonia in intubated patients: role of respiratory airway care. Am J Respir Crit Care Med 1996;154(1):111-115.

7. Dragoumanis CK, Vretzakis GI, Papaioannou VE, Didilis VN, Vogiatzaki TD, Pneumatikos IA. Investigating the failure to aspirate subglottic secretions with the Evac endotracheal tube. Anesth Analg 2007;105(4):1083-1085.

8. Berra L, De Marchi L, Panigada M, Yu ZX, Baccarelli A, Kolobow T. Evaluation of continuous aspiration of subglottic secretion in an in vivo study. Crit Care Med 2004;32(10):2071-2078.

9. Girou E, Buu-Hoi A, Stephan F, Novara A, Gutmann L, Safar M, Fagon JY. Airway colonisation in long-term mechanically ventilated patients: effect of semi-recumbent position and continuous subglottic suctioning. Intensive Care Med 2004;30(2):225-233.

10. Hodd J, Doyle A, Carter J, Albarran J, Young P. Increasing positive end expiratory pressure at extubation reduces subglottic secretion aspiration in a bench-top model. Nurs Crit Care 2010;15(5):257-261.

11. Safdari R, Yazdannik A, Abbasi S. Effect of intermittent subglottic secretion drainage on ventilator-associated pneumonia: a clinical trial. Iran J Nurs Midwifery Res 2014;19(4):376-380.

12. Yang L, Tian WY, Yang YH, Wang C. Clear the secretions above the cuff. Zhonghua Jie He He Hu Xi Za Zhi 1994;17(6):10.

13. Li J, Zhan QY, Liang ZA, Du ML, Dai HP, Sun B, et al. A questionnaire survey on the current practices of respiratory care in intensive care unit in 30 provinces. Zhongguo Wei Zhong Bing Ji Jiu Yi Xue 2009;21(4):211-214.

14. Young PJ, Rollinson M, Downward G, Henderson S. Leakage of fluid past the tracheal tube cuff in a benchtop model. Br J Anaesth 1997;78(5):557-562.

15. Suys E, Nieboer K, Stiers W, De Regt J, Huyghens L, Spapen H. Intermittent subglottic secretion drainage may cause tracheal damage in patients with few oropharyngeal secretions. Intensive Crit Care Nurs 2013;29(6):317-320.

16. Depew CL, McCarthy MS. Subglottic secretion drainage: a literature review. AACN Adv Crit Care 2007;18(4):366-379.

17. Smulders K, van der Hoeven H, Weers-Pothoff I, VandenbrouckeGrauls C. A randomized clinical trial of intermittent subglottic secretion drainage in patients receiving mechanical ventilation. Chest 2002;121(3):858-862.

18. Greene R, Thompson S, Jantsch HS, Teplick R, Cullen DJ, Greene EM, et al. Detection of pooled secretions above endotracheal-tube cuffs: value of plain radiographs in sheep cadavers and patients. AJR 1994;163(6):1333-1337.

19. Li Bassi G, Marti JD, Saucedo L, Rigol M, Roca I, Cabanas M, et al. Gravity predominates over ventilatory pattern in the prevention of ventilator-associated pneumonia. Crit Care Med 2014;42(9):e620e627.

20. Kuchnicka K, Maciejewski D. Ventilator-associated lung injury. Anaesthesiol Intensive Ther 2013;45(3):164-170.

21. Rassam S, Sandbythomas M, Vaughan RS, Hall JE. Airway management before, during and after extubation: a survey of practice in the United Kingdom and Ireland. Anaesthesia 2005;60(10):995-1001.

22. Hodd J, Doyle A, Carter J, Albarran J, Young P. Extubation in intensive care units in the UK: an online survey. Nurs Crit Care 2010;15(6):281-284.

This article is approved for Continuing Respiratory Care Education credit. For information and to obtain your CRCE

(free to AARC members) visit

www.rcjournal.com

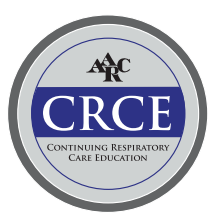

